\title{
Study of the Duration, Outcomes, and Related Factors of Reperfusion Therapy in Patients with ST-Segment Elevation Myocardial Infarction
}

\author{
Hamid Rahimi', Leila Azizkhani2,*iD, Siamak Vahedi ${ }^{3}$, Kourosh Akhbari4, Bahar \\ Adalani $^{5}$, Behzad Khalafi ${ }^{6}$
}

1 General Practitioner, Student Research Committee, Kurdistan University of Medical Sciences, Sanandaj, Iran

${ }^{2}$ Assistant Professor, Department of Emergency Medicine, Kosar Hospital, Kurdistan University of Medical Sciences, Sanandaj, Iran

3 Associate Professor, Department of Cardiology, Tohid Hospital, Kurdistan University of Medical Sciences, Sanandaj, Iran

${ }^{4}$ Assistant Professor, Department of Emergency Medicine, Kosar Hospital, Kurdistan University of Medical Sciences, Sanandaj, Iran

5 Specialist, Department of Emergency Medicine, Kosar Hospital, Kurdistan University of Medical Sciences, Sanandaj, Iran

${ }^{6}$ General Practitioner, Research and Technology Deputy, Kosar Hospital, Kurdistan University of Medical Sciences, Sanandaj, Iran

* Corresponding Author: Leila Azizkhani, Department of Emergency Medicine, Kosar Hospital, Kurdistan University of Medical Sciences, Sanandaj, Iran.Email: leila433@gmail.com

Received: 07.09.2019

Accepted: 22.01 .2020

How to Cite this Article:

Rahimi H, Azizkhani L, Vahedi

S, Akhbari K, Adalani B, Khalafi

B. Study of the Duration,

Outcomes, and Related Factors of Reperfusion Therapy in Patients with ST-Segment Elevation Myocardial Infarction. Avicenna J Clin Med. 2020; 26(4): 220-226. DOI: 10.29252 ajcm.26.4.220

\section{Abstract}

Background and Objective: One of the most important advancements regarding the care of patients with acute myocardial infarction is the administration of anticoagulation medicines (e.g., streptokinase). However, it must be noticed that this medicine requires rapid and timely administration. Moreover, Percutaneous Coronary Intervention (PCI) is increasingly used as a method of revascularization. Considering the importance of time for the effective use of these methods, the present study aimed to investigate the duration of the process, treatment outcome, and its associated factors in patients with ST-segment elevation myocardial infarction (STEMI) who were candidates for streptokinase or PCI.

Materials and Methods: The present descriptive-analytical study made use of total population sampling so that all patients with STEMI who did not meet the exclusion criteria were included in the study in 2017. The study population consisted of 183 patients who had referred to the emergency ward of Tohid Hospital in Sanandaj, Iran. The patients were investigated regarding their age, gender, day of admission, pain-to-admission time, the average travel time to the hospital, type of referral, underlying illness, time of myocardial infarction diagnosis, starting time of reperfusion therapy, and final outcome. The collected data were recorded in the designed forms and then entered into SPSS software (version 22). Descriptive statistics formulas (i.e., mean, standard deviation, and percentage) were used regarding research questions. Moreover, regarding the research hypotheses, the chi-square test and correlation coefficients were used in the case of qualitative and quantitative variables, respectively.

Results: According to the results, the majority of patients were male patients over 50 years old with no history of myocardial infarction. A total of $146(79.8 \%)$ and $37(20.2 \%)$ of participants were male and female, respectively. Moreover, the mean age of the participants was 58.52 and 28 of them (15.3\%) had a history of myocardial infarction. The mean duration time of ECG and myocardial infarction diagnosis was 4.2 and 18.85 min, respectively. Furthermore, the mean duration time from patient admission to receiving intervention was estimated at $107.68 \mathrm{~min}$. It should also be mentioned that their average length of hospital stay was 4.9 days. Conclusion: Based on the results, it can be said that the mortality rate was higher in older patients than in others. Moreover, the duration of ECG in female patients was longer in comparison to the male patients. In addition, starting the reperfusion therapy took longer in the night shifts.

Keywords: Myocardial Infarction, Percutaneous Coronary Intervention, Thrombolytic Therapy 


\section{بررسى مدت زمان فرايند ريّرفيوزنترايى در بيماران دجار سكته قلبى حاد همراه با

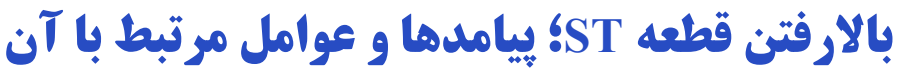

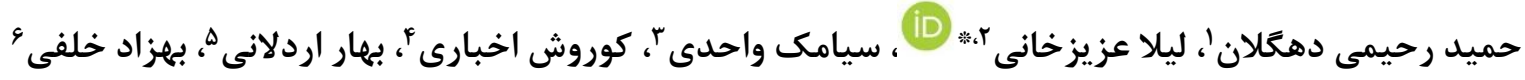

' دكترى حرفهاى يزشكى، كميته تحقيقات دانشجويى، دانشعاه علوم يزشكى كردستان، سنندج، ايران

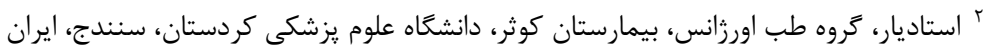

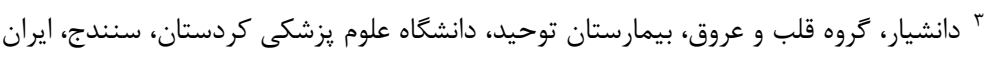

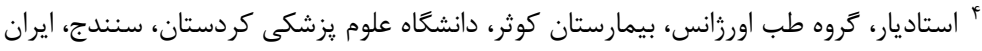

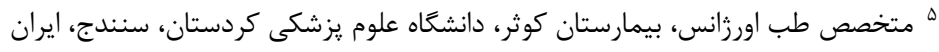

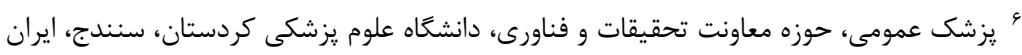
leila433@gmail.com : و نويسنده مسئول: ليلا عزيزخانى، گروه طب اورزانس، بيمارستان كوثر، دانشكاه علوم يزشكى كردستان، سنندج، ايران. ايميل

جكيده سابقه و هدف: يكى از مهمترين يِيشرفتها در زمينه مراقبت از بيماران مبتلا به سكته قلبى حاد، تجويز

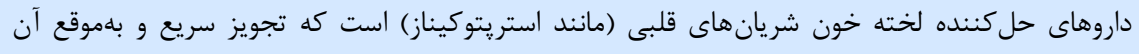

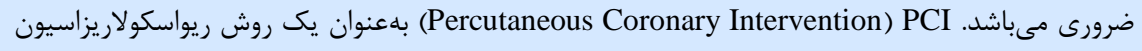

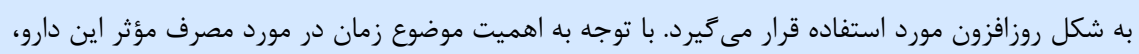

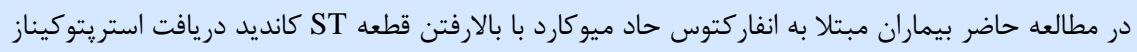

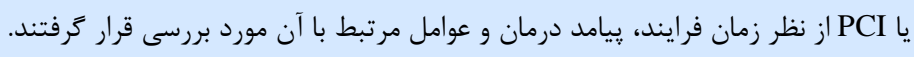

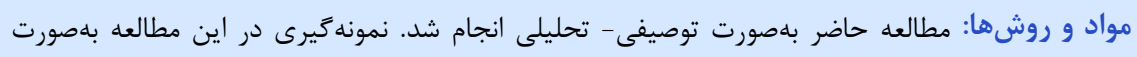

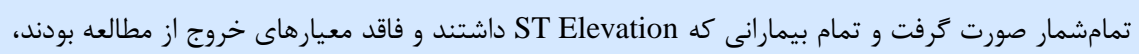

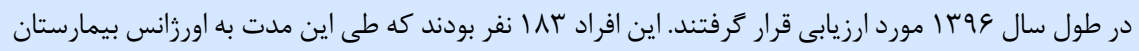

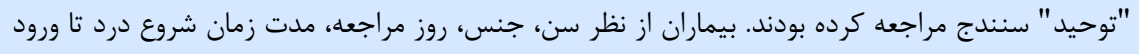

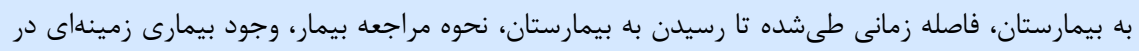

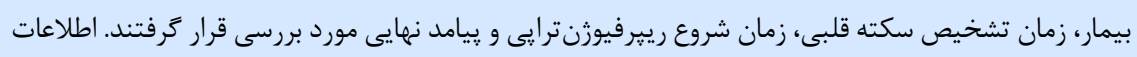

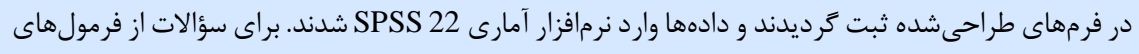

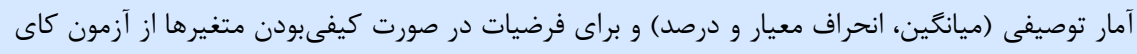

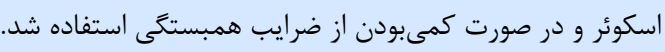

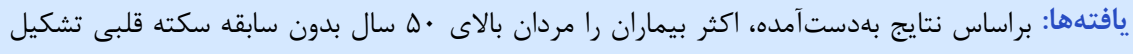

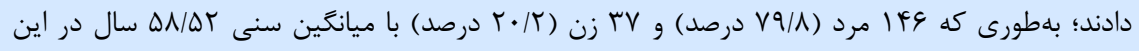

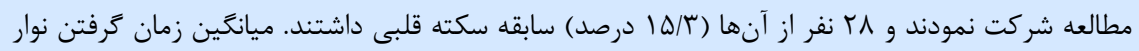

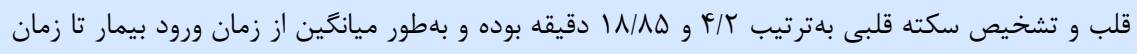

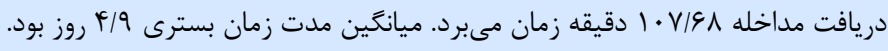

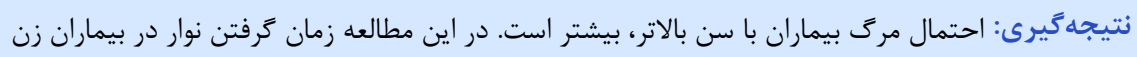

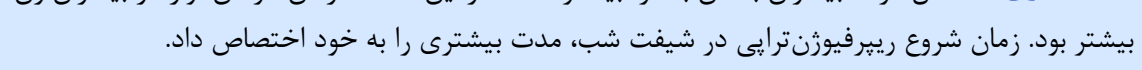
وازَّان كليدى: استريتوكيناز، ترومبوليتيك درمانى، سكته قلبى

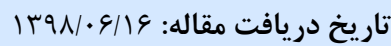

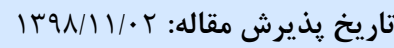
تمامى حقوق نشر براى دانشكاه علوم يزشكى همدان محفوظ است. 
مطالعه حاضر با هدف تعيين مدت زمان فرايند رييرفيوزنترايى

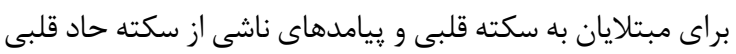

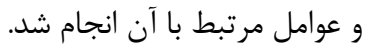

\section{مواد و روشها}

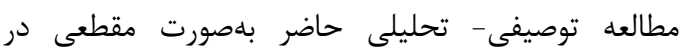

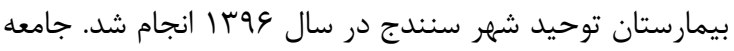

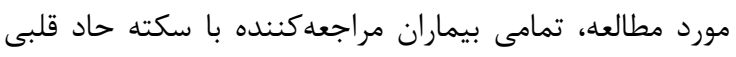
همراه با بالارفتن قطعه ST كه به اورزانس بيمارستان توحيد

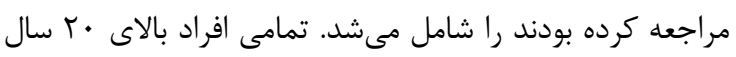

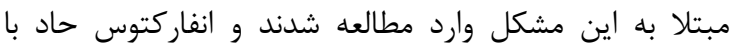

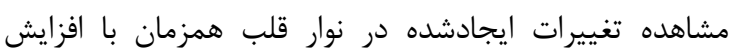

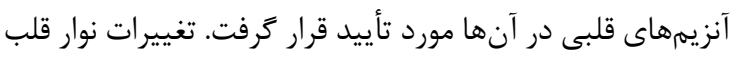

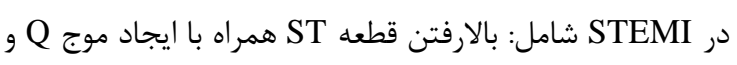
تغييرات T بود. در نوع Non STEMI نيز تغييرات، وِايينافتادن

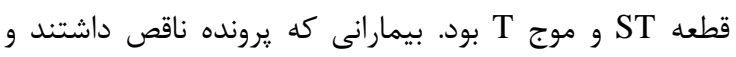

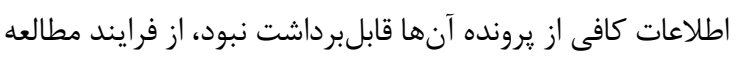
كنار زذاشته شدند.

حجم نمونه و روش نمونهَيرى در اين مطالعه بهصورت

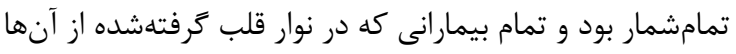

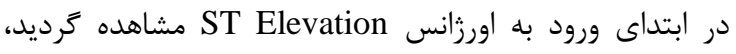

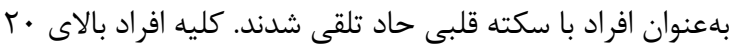

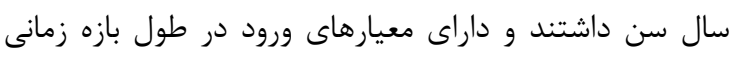

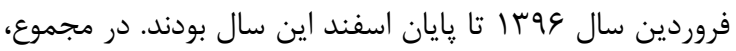
س1/ نفر مورد ارزيابى قرار گرفتند.

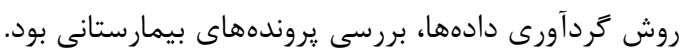

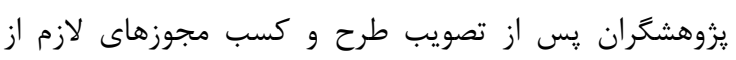

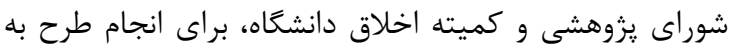

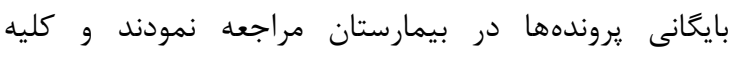
يروندههاى مربوط به بازه زمانى مذكور را از بايكانى استخراج

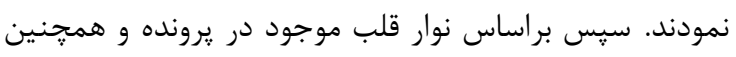

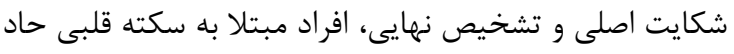

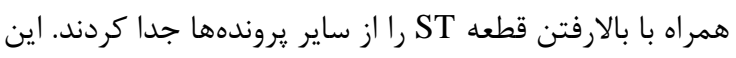

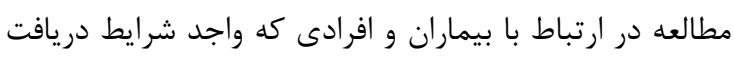
داروهاى ترومبوليتيكترايى و يا آنزيوگرافى كرونر اورزانس إنس

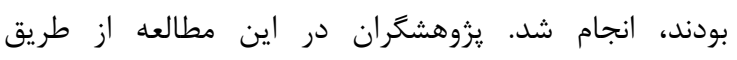
جكليست هايى كه در دست داشتند، كليه اطلاعات مورد نياز

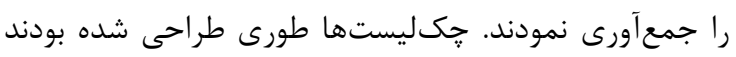

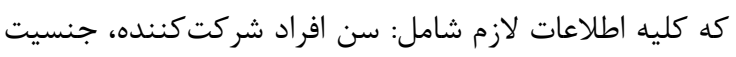

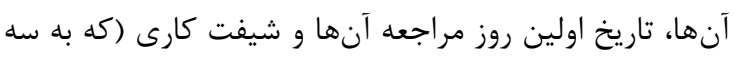

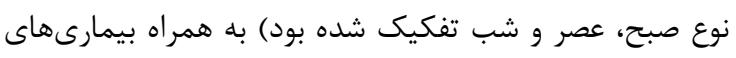

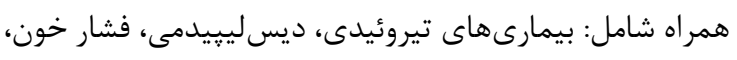

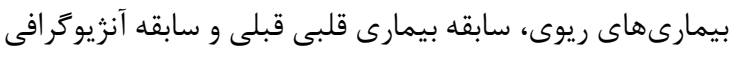

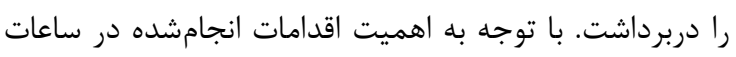

به اورزانس در آمريكا مى باشند. درد قفسه سينه علامتى است كه

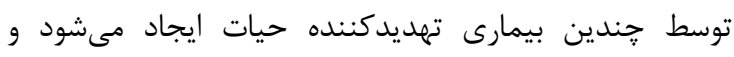

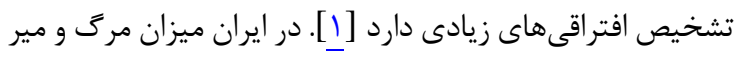

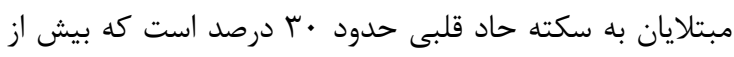

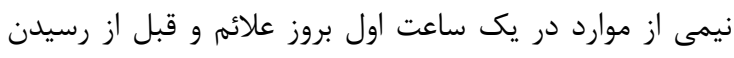

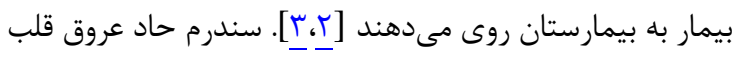
(ACS: Acute Coronary Syndrome)

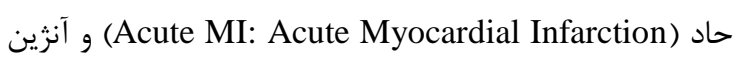
نايايدار (Unstable Angina) مىباشد كه در خطر بالاى سكته قلبى قرار دارند. سكته حاد قلبى در واقع نكروز ميوكارد همراه

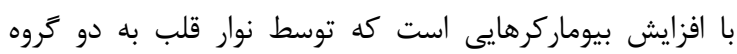
كلى ST Elevation Miocardial Infarction) STEMI) و

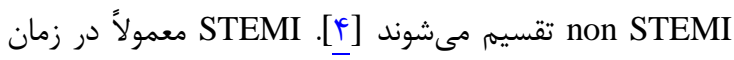
كاهش ناگهانى جريان عروق قلب پِ إن از انسداد ترومبوتيك در

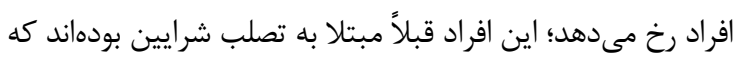

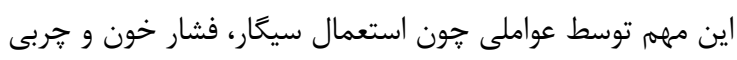

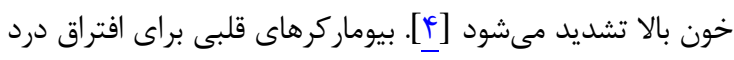

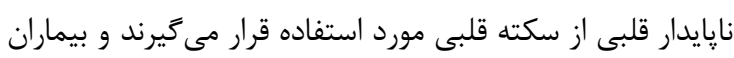

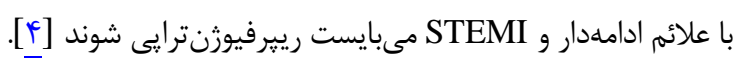

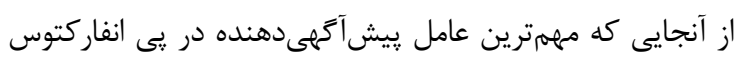

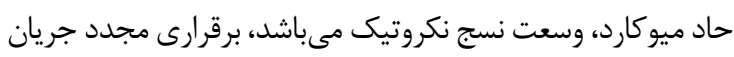

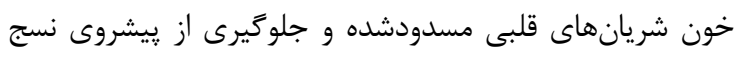
نكروتيك در شش ساعت اول بهويزه طى ساعات اول تا سوم بروز

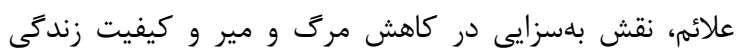

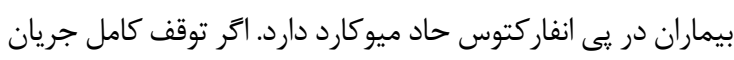

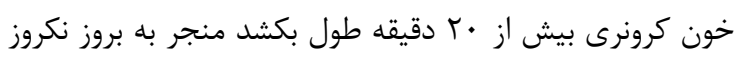

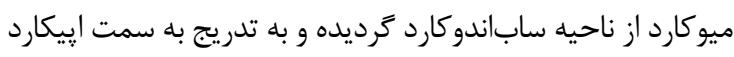

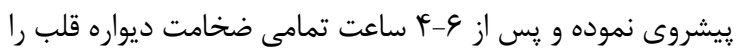
دربرمى

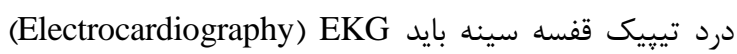

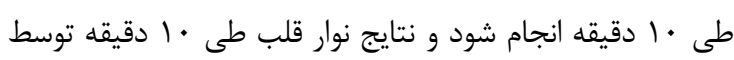

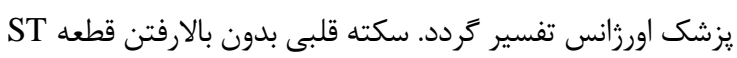

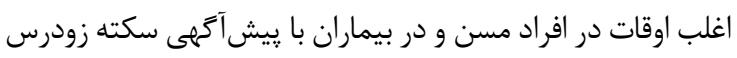

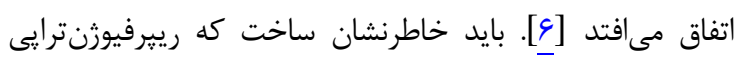

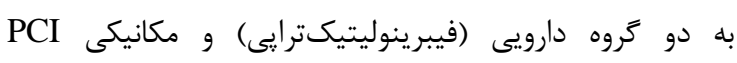
(Percutaneous Coronary Intervention)

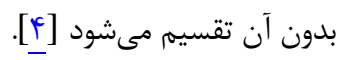

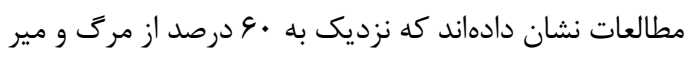

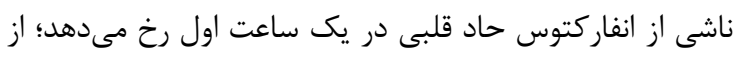

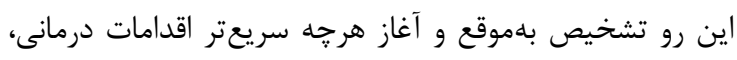

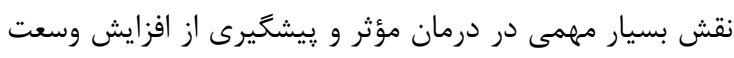

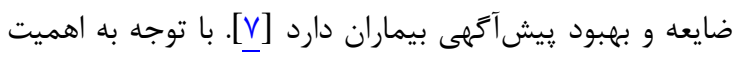

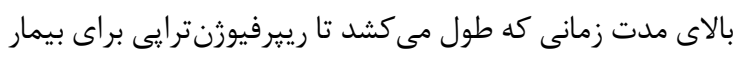

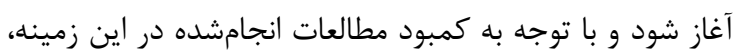


اوليه وقوع سكته قلبى، نحوه مراجعه بيماران به اورزانس نيز

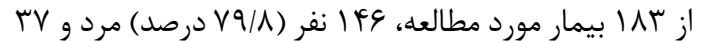

$$
\text { نفر (T/ • د درصد) زن بودند. }
$$

ميانگين سنى شركت كنند

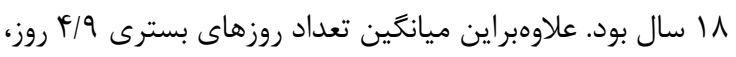

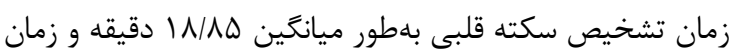

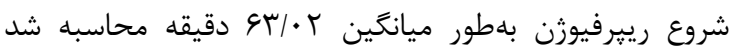

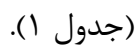

عمدهترين بيمارى زمينهاى در ميان مراجعه كنندكان با سكته

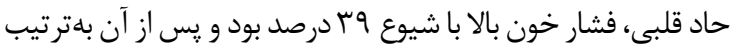

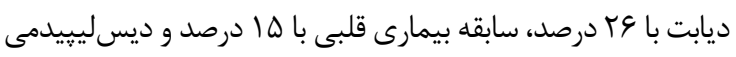

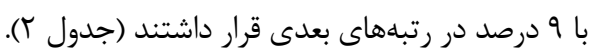

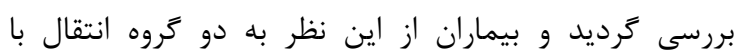

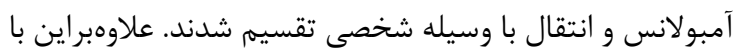

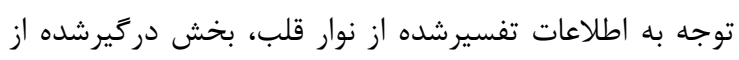

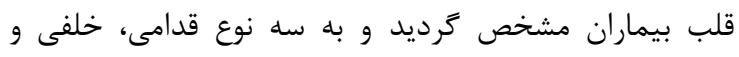

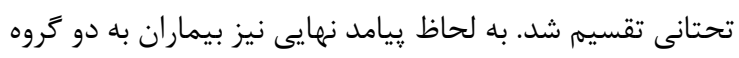
ترخيصشده و فوتنموده تقسيم كرديدند.

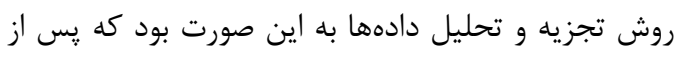

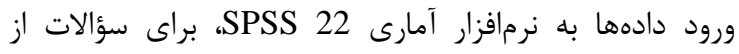
فرمولهاى آمار توصيفى (ميانخين، انحراف معيار و درصد) و وبراى نراى

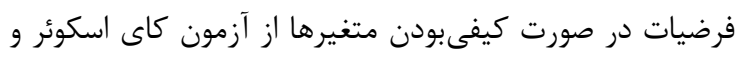
در صورت كمىبودن از ضرايب همبستكى استفاده شد.

جدول ا: اطلاعات توصيفى افراد مورد مطالعه

\begin{tabular}{|c|c|c|c|c|}
\hline انحر اف معيار & ميانگين & حداكثر & حداقل & \\
\hline IT/AT & $\Delta \Lambda / \Delta T$ & 94 & 11 & سن (سال) \\
\hline r/9q & $4 / 99$ & fl & 1 & مدت بسترى (روز) \\
\hline ।1/99 & $1 \cdot 101$ & If. & 1 & زمان شروع درد (ساعت) \\
\hline $\mathrm{V} / 199$ & $F / r$. & $\Delta r$ & • & زمان گَرفتن نوار (دقيقه) \\
\hline rI/Tq & $1 \wedge / \wedge \Delta$ & ir. & - & زمان تشخيص سكته قلبى (دقيقه) \\
\hline$F V / I$ & $q \mu / \cdot r$ & r.. & $\Delta$ & زمان شروع رييرفيوزن (دقيقه) \\
\hline$\Delta F / \Lambda G$ & $1 \cdot V / 9 \wedge$ & re. & $r \cdot$ & مدت كلى مداخله (دقيقه) \\
\hline
\end{tabular}

جدول ب: فراوانى بيمارىهاى زمينهاى در افراد مورد مطالعه

\begin{tabular}{|c|c|c|c|c|}
\hline درصد تجمعى & درصد & فراوانى كل & وضعيت & \\
\hline$V T / T$ & $V r / r$ & IrF & عدم ابتلا ل & \multirow{2}{*}{ ديابت } \\
\hline $1 \cdots$ & r\&/A & $4 q$ & مبتلا & \\
\hline $4 \cdot / V$ & $9 \cdot / V$ & 111 & عدم ابتلا ل & \multirow{2}{*}{ فشار خون بالا } \\
\hline $1 \cdots$ & $r q / r$ & vr & مبتلا & \\
\hline $1 \cdots$ & $1 \cdots$ & IN & عدم ابتلا & \multirow{2}{*}{ بيمارى ريوى } \\
\hline $1 \ldots$ & $\cdot$ & • & مبتلا & \\
\hline$q \Lambda / 4$ & $9 \Lambda / \uparrow$ & $1 \wedge$. & عدم ابتلا ل & \multirow{2}{*}{ اختلالات تيروئيدى } \\
\hline $1 \cdots$ & 1/9 & r & مبتلا & \\
\hline$q \cdot / V$ & $q \cdot / v$ & 199 & عدم ابتلا & \multirow{2}{*}{ ديس ليبيدمى } \\
\hline $1 \cdots$ & $9 / \pi$ & IV & مبتلا & \\
\hline$\Lambda F / \vee$ & $\Lambda F / V$ & $10 \Delta$ & 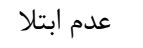 & \multirow{2}{*}{ سابقه بيمارى قلبى } \\
\hline $1 \cdots$ & $10 / \pi$ & r^ & مبتلا & \\
\hline $1 \cdot / 9$ & $1 \cdot / 9$ & $1 F A$ & 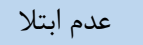 & \multirow{2}{*}{ سابقه آنزيوگرافى } \\
\hline $1 \cdots$ & $19 / 1$ & ra & مبتلا & \\
\hline$|f| / d$ & $41 / 0$ & Ve & صبح & \multirow{3}{*}{ شيفت مراجعه بيمار } \\
\hline $9 N / 9$ & $T V / T$ & $\Delta \cdot$ & 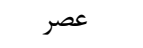 & \\
\hline $1 \cdots$ & $r 1 / 1$ & $\Delta V$ & شب 1 & \\
\hline 94 & 94 & IVT & ترخيص & \multirow{2}{*}{ بيامد نهايى براى بيمار } \\
\hline $1 \cdots$ & 9 & 11 & مرى & \\
\hline$r M / l$ & $r 1 / 1$ & $\Delta \Delta$ & آمبولانس & نحوه مراجعه به \\
\hline $1 \cdots$ & $\vee \cdot$ & 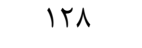 & ساير وسايل & اورزانس \\
\hline
\end{tabular}




\begin{tabular}{|c|c|c|c|c|}
\hline & & & & ادامه جدول r. \\
\hline$\Delta \cdot / r$ & $\Delta \cdot / \mu$ & 94 & قدامى & \multirow{4}{*}{ بخش درگيرشده در } \\
\hline $1 \cdot / 9$ & $r \cdot 19$ & $\Delta \varphi$ & تحتانى & \\
\hline $91 / 9$ & 11 & rז & سه ركى & \\
\hline $1 \cdots$ & 1/1 & r & خلفى & \\
\hline
\end{tabular}

جدول بّ: بررسى رابطه متغيرهاى دمو گرافيك با سوابق بيمارى در افراد مورد مطالعه

\begin{tabular}{|c|c|c|c|c|c|c|}
\hline \multicolumn{2}{|c|}{ ييامد مرى (درصد) } & \multicolumn{2}{|c|}{ جنس (درصد) } & \multicolumn{2}{|c|}{ ميانَين سنى (سال) } & \\
\hline سالم & مبتلا & زن & مرد & عدم ابتلا & مبتلا & \\
\hline$F / Q$ & $1 \cdot \pi$ & rF & rI & $\Delta V / F i$ & दा/DD & ديابت \\
\hline$V / r$ & $F / r$ & is & rt & $\Delta V / F i$ & G./Tr & فشار خون بالا \\
\hline $9 / 0$ & $\wedge$ & ir & v & $\Delta \Lambda / \Gamma q$ & $9 \cdot 111$ & ديسليبيدمى \\
\hline$I V / Q$ & $r / 9$ & 11 & 19 & $\Delta \Lambda / T V$ & $\Delta 9 / 9 r$ & سابقه سكته قلبى \\
\hline$F / V$ & $11 / 4$ & r & r & $\Delta V / 9 V$ & GY/DT & سابقه آنثيوگرافى \\
\hline - & - & $1 \pi / 0$ & $\varphi / l$ & $\Delta \mathrm{V} / \mathrm{V}$ & $v \cdot / 11$ & مرت بيمار \\
\hline$r / Q$ & $\mid F / Q$ & rt & $r \wedge$ & $\varepsilon N / T^{R}$ & GFIDT & وسيله انتقال آمبولانس \\
\hline
\end{tabular}

كه خود نيازمند وجود كادر مجرب جهت تشخيص درست و درمان

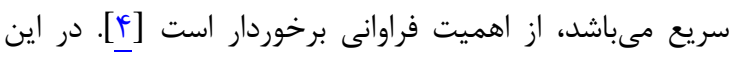

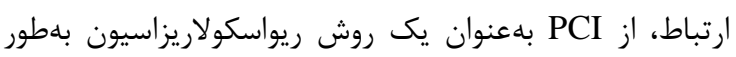

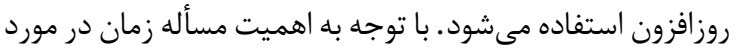

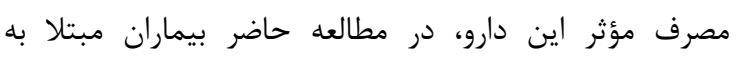

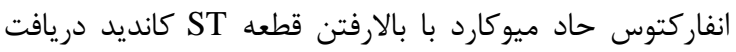

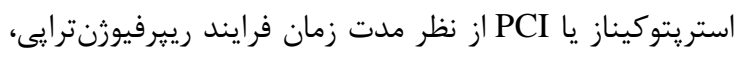

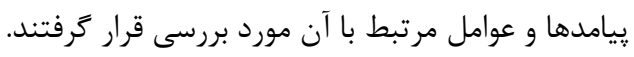

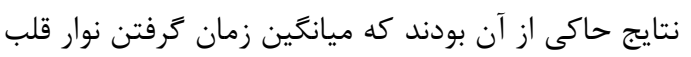

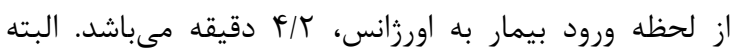

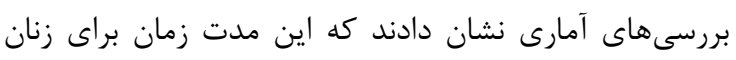

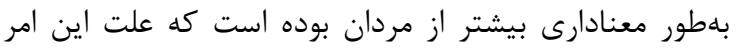

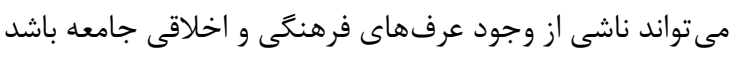

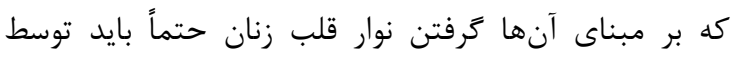

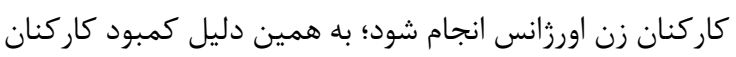

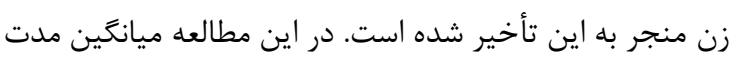

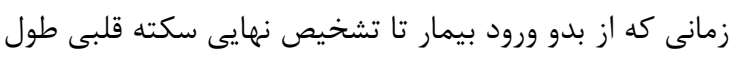

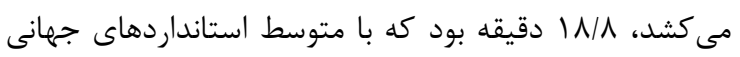

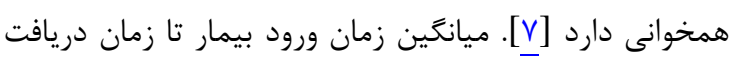

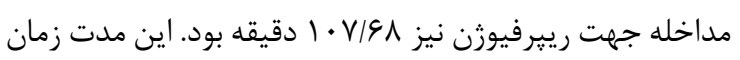

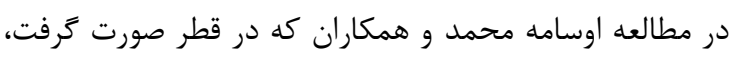

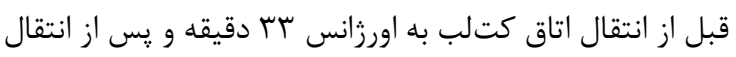

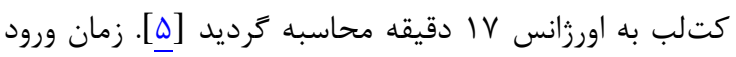

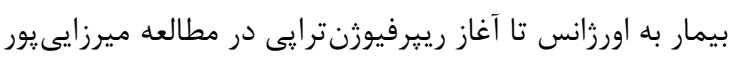

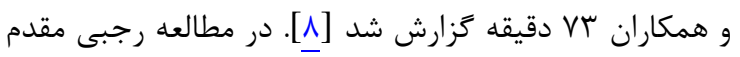

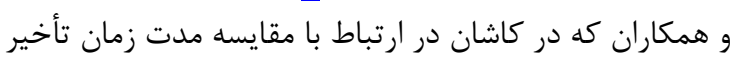

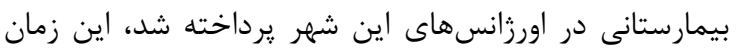

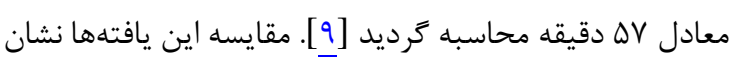

جدول ץ به بررسى ارتباط سن، جنس و يِيامد نهايى بيمارى

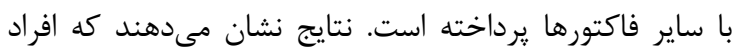

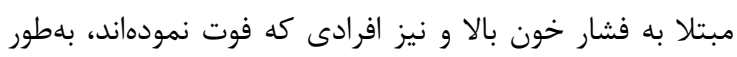

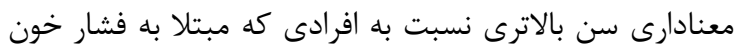

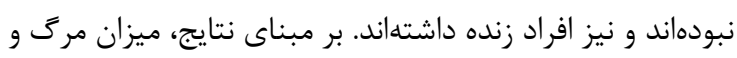

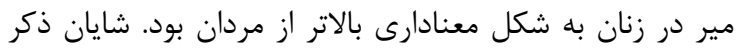

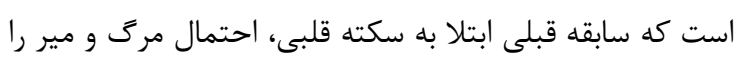

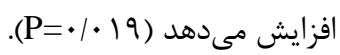

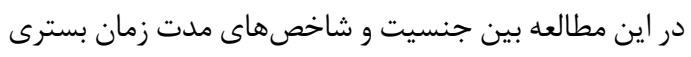

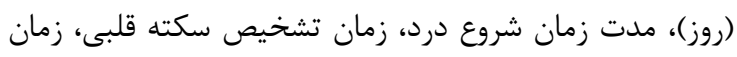

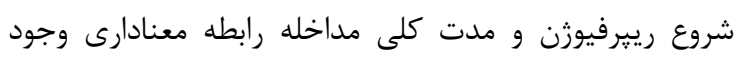

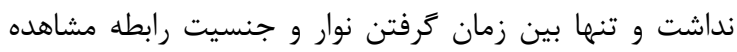

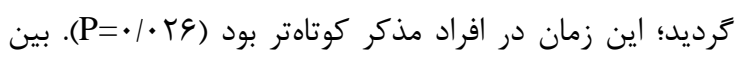

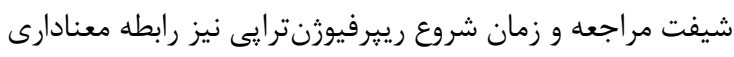

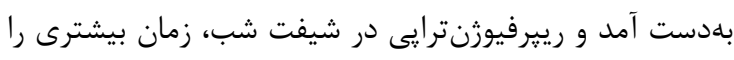

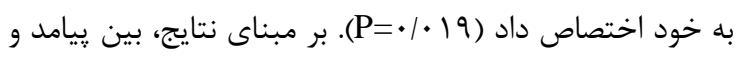

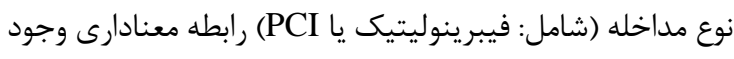

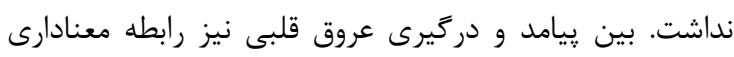

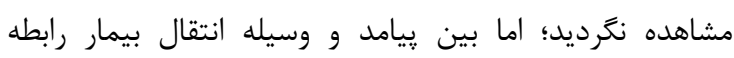

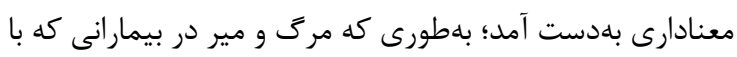

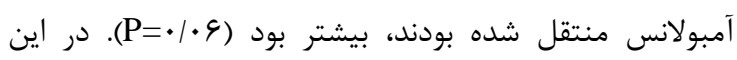

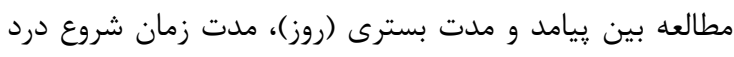

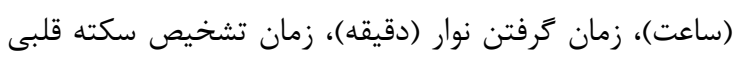

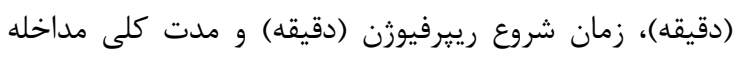
(دقيقه) رابطه معنادارى وجود نداشت.

شروع درمان مناسب و بهموقع پس از ورود بيمار به بيمارستان 
كه سكته قلبى با كاهش عملكرد قلب، موجبات اين را فراهم

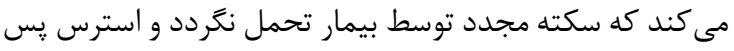

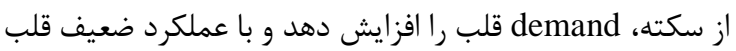

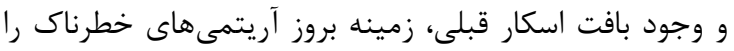

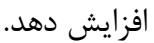

در اين مطالعه بين نحوه انتقال بيماران به اورزانس و پيامد

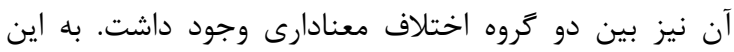

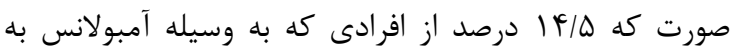

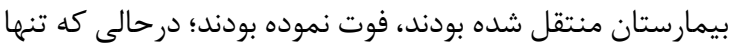

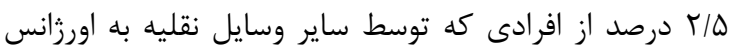

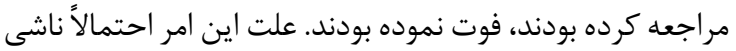

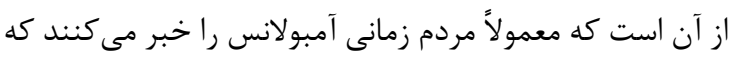

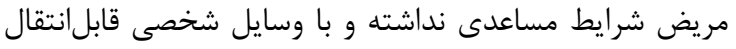

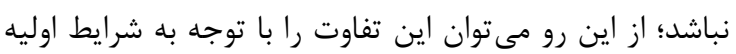
بيمار توجيه كرد. از سوى ديكر از نظر بيمارىهاى زمينهاى، لو لو نفر فشار

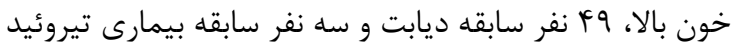

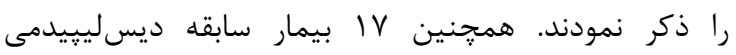

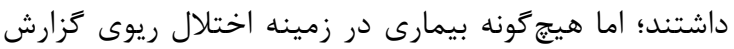

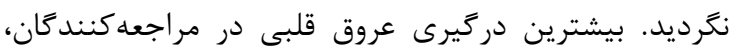

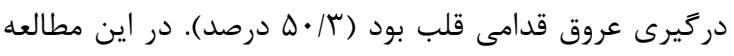

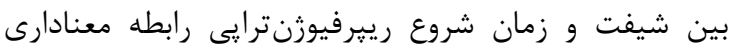

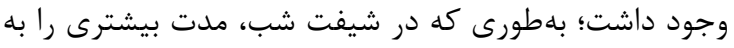

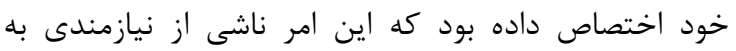

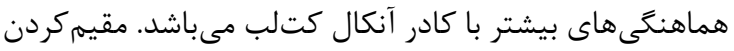

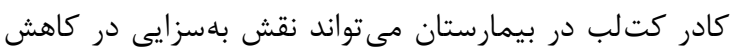
اين زمان داشته باشد. در اين مطالعه بين بيامد و نوع مداخله، رابطه معنادارى وجود

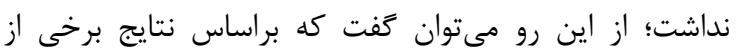
مطالعات، تفاوتى بين PCI و داروهاى ترومبوليتيك در درن نتيجه

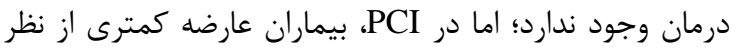
احتمال خونريزى را تحمل مى كنيند. براى نتيجه كيرى كلى نلى نبايد

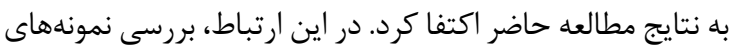

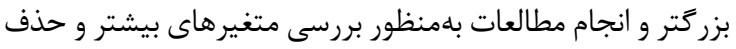

مخدوش كنندهها توصيه مىشود.

\section{نتيجه تيرى}

نتايج اين مطالعه نشان دادند كه احتمال فوت بيماران با سن

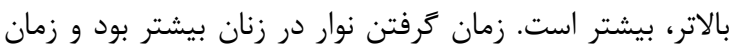

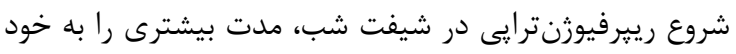

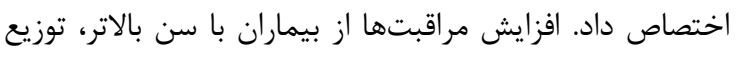

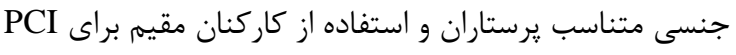

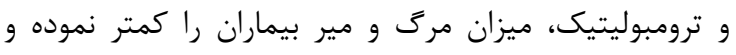

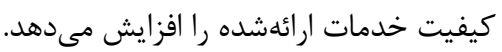

مىدهد كه مدت زمان "درب تا بالن" بيماران سكته قلبى در

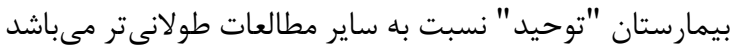

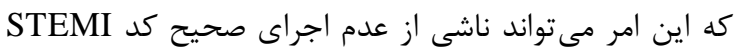

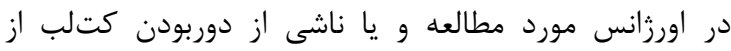

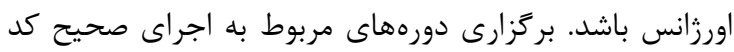
STEMI مطالعه اوسامه محمد و همكاران نيز ززارش شده است) مى تواند در كاهش اين زمان مؤثر باشد.

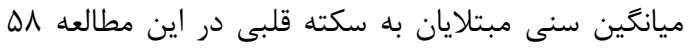

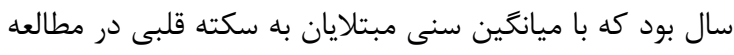

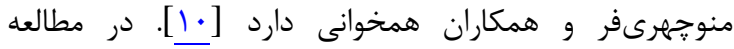
رحيمزاده و همكاران كه در آن طى يك همرئ مرور سيستماتيك به دانه

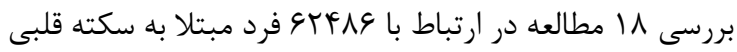

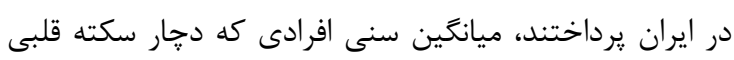

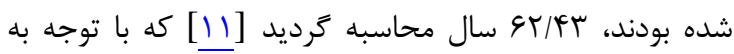

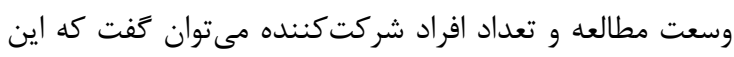
عدد به واقعيت نزديكتر مىباشد.

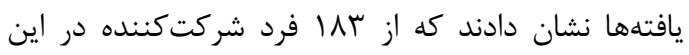

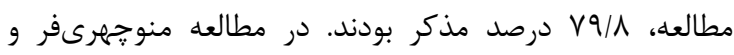

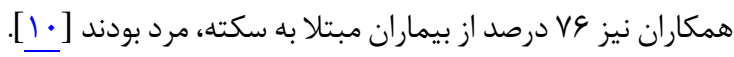

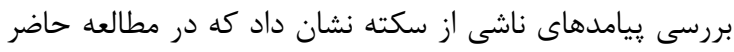

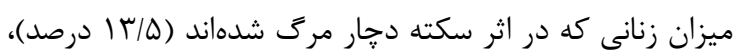

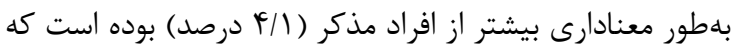

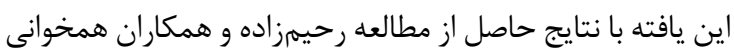

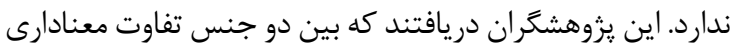

از نظر ييامد وجود ندارد [11]

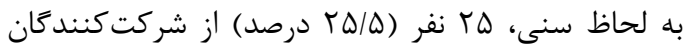

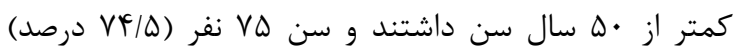

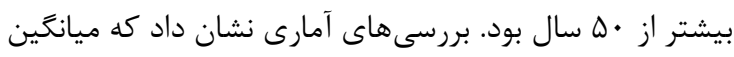

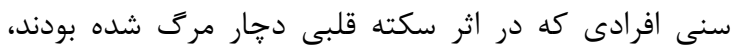

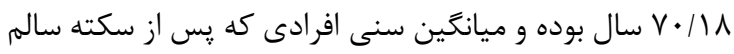

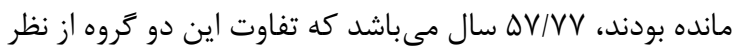

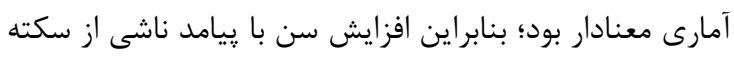
قلبى ارتباط دارد. در مطالعه حاضر وب درصد از شركت كنند

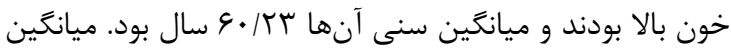
سنى افراد فاقد سابقه فشار خون بالا نيز DV/FT سال محاسبه

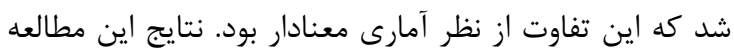

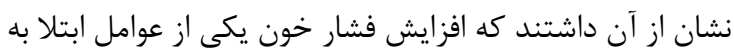

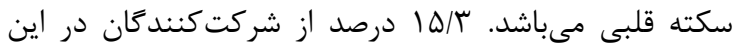

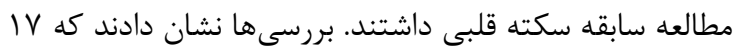

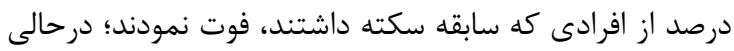

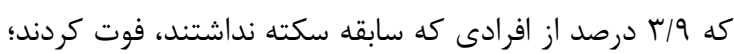
اين تفاوت از نظر آمارى معنادار بود. اين امر ناشى از آن است دادئه 
سمهم نو سيندكان

نويسنده اول (يزوهشكر اصلى): نوشتن يرويوزال، جمعآورى

دادها، تدوين مقدمه، روششناسى و نكارش مقاله: DL

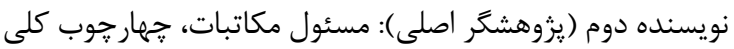

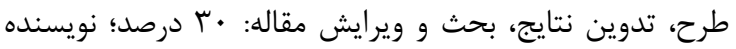

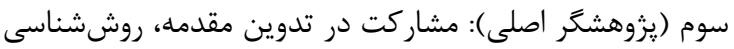

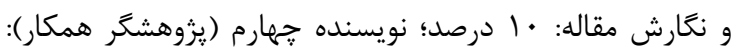
مشاركت در تدوين نتايج و بحث: ه درصد؛ نويسنده رينجم

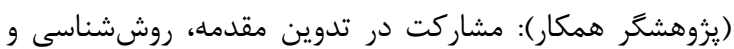

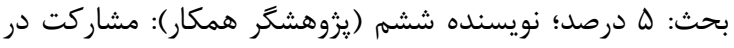

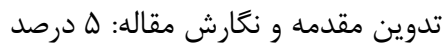

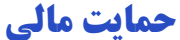

هزينه انجام طرح توسط معاونت تحقيقات و فناورى دانشخاه

$$
\text { علوم يزشكى كردستان تأمين شده است. }
$$

\section{REFERENCES}

1. Marx J, Walls R, Hockberger R. Rosen's emergency medicine-concepts and clinical practice. $8^{\text {th }}$ ed. Philadelphia: Elsevier Health Sciences; 2014. P. 214.

2. Jabbad HH, Elgaby E, Alama MN. Improving door to needle thrombolysis in acute ST-elevation myocardial infarction. Saudi J Internal Med. 2015;5(1):19-23. DOI 10.32790/sjim.2015.5.1.4

3. Puskarich MA, Jones AE. Tintinalli's emergency medicine: a comprehensive study guide. New York: McGraw-Hill Education; 2015. P. 16

4. Kasper D, Fauci A, Hauser S, Longo D, Jameson J. Harrison's principles of internal medicine. $19^{\text {th }}$ ed. New York: McGrawHill; 2015. P. 325, 1595, 1599, 1605.

5. Mohammed O, Paramba FC, Aboobaker NV, Mohammed RA, Purayil NK, Jassim HM, et al. Reduction in door-toneedle time after transfer of thrombolysis site from CCU to emergency department Emerg Med Int. 2013;2013:208271. PMID: 24205437 DOI: 10.1155/2013/208271

6. Mann DL, Zipes DP, Libby P, Bonow RO. Braunwald's heart disease: a textbook of cardiovascular medicine. Philadelphia: Elsevier Health Sciences; 2014. P. 1107.

7. Marjani K, Solaimanpoor M, Allahmoradi Z, Etemadi V, Noori M. Clinical audit duration of streptokinase injection process in patients with myocardial infarction in Tabriz
تشك و قدر قاذّى

اين مقاله بركرفته از يايان نامه دوره دكترى حرفهاى يزشكى

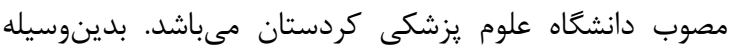

نويسند

فناورى دانشعاه و همكارى بيماران محترم اعلام مى مينمايند.

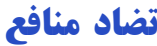

نتايج اين مطالعه با منافع نويسندكان در تعارض نمىباشد.

\section{مالا حظات اخلاقى}

اين مطالعه داراى تأييديه از كميته اخلاق دانشعاه علوم

يزشكى كردستان مىباشد (IR.MUK.REC.1397.132). لازم

به ذكر است كه تمامى اطلاعات بهدستآمده از يروندهها بهصورت

محرمانه در اختيار يزوهشخران قرار گرفتند و بدون مجوز از

معاونت تحقيقات و فناورى دانشگاه در اختيار هيج فرد حقيقى و

حقوقى قرار داده نشدند.

Shahid Mahallati Hospital in 2011-2012. First Conference on Clinical Audit and Quality Improvement, Aliabad-e Katul, Iran; 2018. [In Persian]

8. Mirzaee Poor F, Forood A, Masoomi M, Rashidinejad H, Soroor Azimzadeh B, Ghazanfari A. Assessing time between arriving to hospital and administration of streptokinase in patients with acute myocardial infarction in emergency department of Kerman University of Medical Sciences in 2003-4. J Kerman Univ Med Sci. 2008;15(3):217-23. [In Persian]

9. Rajabi-Moghadam H, Raygan F, Nourddini M, Mousavi SG, Taghadosi M, Zahedi M. Evaluating in-hospital delay for fibrinolytic therapy of myocardial infarction patients with acute ST-elevation in Kashan Shahid-Beheshti hospital during 2007-2010. Feyz. 2012;16(5):468-75. [In Persian]

10. Manouchehrifar M, Ghasemi S., Shojaee M, ShahhosseiniT, Lashgari A. Characteristics of patients with myocardial infarction admitted to the emergency department; a five years epidemiological study. Iran J Emerg Med. 201;3(4):138-42.

11. Rahimzadeh M, Kavehei B. Short-term survival rates after myocardial infractions in Iran: meta-analysis and systematic review. J Arak Univ Med Sci. 2017;20(120):5767. [In Persian] 